\title{
Social and Psychosocial Factors Affecting Eating Habits Among University Students in Syria: A Cross- Sectional Study
}

Homam Alolabi

Syrian Private University

Mhd Obai Alchallah ( $\square$ obay.1997@gmail.com )

Syrian Private University https://orcid.org/0000-0003-0096-6756

Fatema Mohsen

Syrian Private University

Marah Marrawi

Syrian Private University

Zaynab Alourfi

Syrian Private University

Research

Keywords: Eating habits, Lifestyle, Syrian university students, Social and psychological

Posted Date: June 3rd, 2021

DOl: https://doi.org/10.21203/rs.3.rs-559421/v1

License: (c) (1) This work is licensed under a Creative Commons Attribution 4.0 International License. Read Full License 


\section{Abstract}

Background: Syrian eating habits are trending towards westernized patterns that are high in carbohydrates, fats, and meat. This accompanied by an increasingly sedentary lifestyle has affected young adults' dietary habits. As a consequence, obesity and overweight young adults are significantly increasing in prevalence. This study aims to assess the pattern of eating habits and their relation with psychosocial factors among university students. The objective of this study is to identify factors associated with eating habits and psychological factors.

Methods: A cross-sectional study was conducted among Syrian Private University students using a selfadministrated questionnaire. The questionnaire consisted of 3 sections: socio-demographic characteristics, eating habits, and psychosocial factors. Hierarchical multivariate linear regression was used to obtain factors associated significantly with eating habit score and psychological factors.

Results: Of 728 students included in the study 398 (54.7\%) were females. Overweight and obese participants represented $154(21.4 \%)$ and 49 (6.8\%) respectively. $316(43.4 \%)$ were smokers and 135 (18.5\%) drank alcohol. Only $233(32 \%)$ and $306(42 \%)$ had meals and breakfast regularly respectively. Participants' mean total of eating habits was 5.96 (SD \pm 1.95$)$. Multivariate analysis revealed smoking, exercising, living with family, and "eat because of feeling happy" were factors significantly associated with eating habits score and psychological factors $(p<0.05)$.

Conclusions: Most of the students demonstrated healthy eating habits. The identified socio-demographic factors associated with eating habits can be used to provide lifestyle modification advice via health promotion programs targeted at these specific groups.

\section{Background:}

The new introduction of "Western food", shifting from a healthy Mediterranean cuisine towards an outstripped domestic production of unhealthy deep-fried junk, has had its toll on many countries including Syria. Unhealthy lifestyles and poor eating habits are among the leading causes for developing obesity and non-communicable diseases (NCD) such as type 2 diabetes, cardiovascular disease, and cancer $(1,2)$. NCD, responsible for 36 million deaths/year, is the prime reason for morbidity and mortality worldwide (3). In 2010, an estimated 472.7 males and 326.2 females per 100,000 died from cardiovascular diseases and 65.7 males and 47.2 females per 100,000 died from cancers in Syria (4).

Alarmingly, chronic diseases are now affecting younger generations (5). The transition from school to university presents new challenges for students' diet and lifestyle habits. University life is a critical period where lifelong lifestyle habits are established, choosing the wrong habits will have long-term impacts on the development of chronic diseases in the future (6). Moreover, young adults are prone to obesity (7), and many students gain weight during the transition to higher education $(8,9)$. Several changes in physical growth and psychological development make young students a nutritionally vulnerable group that neglects to meet the dietary requirements (10-12). Environmental and social factors may lead to 
unhealthy eating habits, for example, students tend to adopt unhealthy eating patterns including skipping meals, disfavor homemade food, snack, opt for cheap quick food, and consume fast food (11-13). This raises health concerns when unhealthy habits obtained at this young period remain in later adult life (14, 15). The poor eating habits acquired in university life have been attributed to stress, high workload, and tight schedules (16). Psychological factors such as bad coping strategies during stressful situations including university exams have been found to seriously damage students' eating behaviors $(17,18)$. Studies among medical students have highlighted inadequate eating habits and their relation to university stress $(19,20)$. Therefore, promoting healthy eating habits across young people is essential to ensure healthy wellbeing (10). Raising awareness regarding healthy eating diets through university nutritional campaigns has been advised to prevent $\operatorname{NCD}(21,22)$.

During the Syrian war, a massive downfall in the agricultural sector was recorded. Different factors contributed to this collapse. Many lands/regions/governorates had been taken from government control, and bombed, rendering them unsuitable for cultivation. The shortage of electricity, the imposed sanctions, and the destruction of infrastructure by the terrorist attacks also contributed to the collapse of Syria. All the above have resulted in the decrease of the agricultural labor force forcing local farmers to emigrate from the country. 2014 marked a reduction by $47.53 \%$ and $64.18 \%$ of wheat and olive production respectively (23). This severely affected Syrian nutritive intake where 12.4 million people are food insecure, and 1.3 million are severely food insecure (24).

While some studies have been conducted to assess eating habits and dietary intake among countries in the Middle East $(19,25)$, only a few studies focused on the dietary intake of adolescents in Syria $(26,27)$. The Syrian studies revealed bad eating habits such as skipping breakfast, binge night eating, and an inadequate intake of fruits, vegetables, meat, and dairy products $(26,27)$. Thus, we aimed to assess eating habits and psychological factors among students in a Syrian university. The objectives of this study are to evaluate the association of eating habits with socio-demographic characteristics and to identify factors associated with eating habits, and psychological factors among students in a Syrian university.

\section{Methods:}

\section{Study setting, and participants:}

This online cross-sectional study was conducted in December 2020 using a convenience sampling method among university students of the Syrian Private University (SPU) in Damascus, Syria. Students were asked to participate voluntarily. They were informed all of their responses were recorded anonymously, response to all questions was not mandatory, and were allowed to opt-out of the survey at any time. The aims and objectives of the study were explained to students in a written form attached to the questionnaire. The sample size calculated was 357 based on a margin of error of $5 \%$, and a confidence interval of $95 \%$, for a population of 5,000 students using a sample size calculator. Ethical 
approval was obtained from the Institutional Review Board (IRB), Faculty of Medicine, Syrian Private University.

\section{Study instruments:}

A self-administered self-completed English-language validated questionnaire on eating habits was adopted from previously published studies $(19,20,25)$. The questionnaire contained 3 sections:

1- Socio-demographic information included 10 questions on age, gender, faculty, marital status, financial status, living circumstances, body mass index (BMI), smoking status, alcohol consumption, and exercise.

2- Eating habits and type of meals consumed included 11 questions (20).

3- Psychological factors that influence the dietary eating habits of respondents were assessed using a 6item scale. The validated compulsive eating scale (CES) was used to measure uncontrolled eating patterns among university students (28).

\section{Statistical analysis:}

Data were analyzed using the Statistical Package for Social Sciences version 25.0 (SPSS Inc., Chicago, IL, United States) and reported as frequencies and percentages (for categorical variables) or means and standard deviations (SD) (for continuous variables). The BMI was calculated as weight in kilograms divided by height in square metres $(\mathrm{kg} / \mathrm{m} 2)$. Students' BMI were divided into 4 groups: $<18.5 \mathrm{~kg} / \mathrm{m} 2$ was categorised as underweight, $18.5-24.9 \mathrm{~kg} / \mathrm{m} 2$ was categorised as healthy weight, $25-29.9 \mathrm{~kg} / \mathrm{m} 2$ was categorised as overweight, and $>30 \mathrm{~kg} / \mathrm{m} 2$ was categorised as obese. Each item of eating habits was scored (1) if the response was healthy or (0) if unhealthy. All items were summed and the total score was obtained (minimum $=0$ and maximum $=10$ ). Thus, a higher score on eating habits indicated better eating habits. The t-test was applied to compare the mean eating score against socio-demographic variables (gender, faculty, marital status, exercise, and alcohol consumption). The chi-square test was applied to assess the relationship between the mean eating score and psychological factors. One-way analysis of variance (ANOVA) was applied using f-test to compare mean eating scores against socio-demographic variables (study year, financial status, living circumstances, BMI, and smoking status). Hierarchical multivariate linear regression was used to obtain factors associated significantly with eating habit score. Age, faculty, smoking, drinking alcohol, exercise, and accommodation status were entered in the first step. In the second step, psychological factors affecting eating behavior were entered. Multicollinearity was checked between independent variables. Statistical significance was set at $p<0.05$.

\section{Results:}

\section{Socio-demographic characteristics:}


Of 728 students who participated in the study, 330 (45.3\%) were males, and 398 (54.7\%) were females. Most of the participants were from the medicine 235 (32.3\%), pharmacy 187 (25.7\%), and dentistry 128 (17.6\%) faculties. Second year students $183(25.1 \%)$ represented a majority, whereas third year students $103(14.1 \%)$ represented a minority. The majority were single 606 (83.2\%) and living with their family 564 (77.5\%). 387 (53.2\%) were non-smokers and 593 (81.5\%) never drank alcohol. 268 (36.8\%) participated in sporting activities 1-2 times/week, while $266(36.5 \%)$ had never practiced sport. 593 (81.5\%) reported sleeping between 6 to 10 hours daily. The majority 443 (61.7\%) were within the healthy BMI range, 154 (21.4\%) were overweight, 72 (10.0\%) were underweight, and 49 (6.8\%) were obese (Table 1$)$.

\section{Eating habits:}

Only 259 (36.0\%) students reported they adopted healthy eating habits. Students who ate regular meals, and breakfast represented 233 (32.0\%), and 422 (57.9\%) respectively. The majority $508(69.8 \%)$ of participants ate their meals without having snacks for 3 or more times/week, and $220(30.2 \%)$ had snacks more than 3 times/week.

The majority consumed vegetables and fruits regularly, 471 (64.7\%) and 419 (57.6\%) respectively. Only $232(31.8 \%)$ reported having fried food for 3 or more times/week. Unfortunately, most participants 497 (68.2\%) drank less than 2 liters of water daily. A majority 565 (77.6\%) ate food with family and friends for 3 or more times/week. Almost all participants 652 (89.6\%) knew the importance of eating a well-balanced diet (meat, vegetables, and others), while only $44(6.0 \%)$ and 18 (2.5\%) reported eating mainly vegetables and mainly meat respectively (Table 2 ).

\section{Psychological factors affecting eating behavior:}

Surprisingly $309(42.1 \%)$ students ate because of feeling lonely, 314 (43.1\%) felt out of control with regards to food, and $320(43.6 \%)$ ate until they felt their stomach hurts. When asked if their mood affected their eating behavior, 235 (32.3\%), 476 (65.4\%), and 535 (73.5\%) ate because of feeling nervous/upset, bored, and happy respectively (Table 3 ).

\section{Association between eating habits and socio-demographic characteristics:}

The mean total score of eating habits for all participants was $5.96( \pm 1.95)$, ranging between 0 and 10 . The mean eating score was compared with socio-demographic characteristics. A series of one way ANOVA analyses and t-test analysis revealed that mean eating scores differed significantly across the study year $(p=0.037)$, accommodation status $(p<0.001)$, practicing sport $(p=0.001)$, and smoking $(p<$ $0.001)$. Students in the sixth year had the highest score $6.55( \pm 2.24)$ compared with other year group mean scores, while students in the fifth year had the lowest score $5.67( \pm 2.08)$ compared with other year 
group mean scores $(p=0.037)$. Students living with their families $6.26( \pm 1.89)$ showed a higher mean score compared to those living with friends $5.16( \pm 1.73)$ or alone $4.81( \pm 1.85)(p<0.001)$. Students practicing sports $>3$ times/week $6.37( \pm 1.93)$ showed higher scores than those who played sports $<3$ times/week $5.81( \pm 1.94)(p=0.001)$. Students who never smoked 6.25( \pm 1.86$)$ had higher mean scores than current smokers $5.59( \pm 2.02)$ and previous smokers $6.08( \pm 1.55)(p<0.001)$ (Table 4).

\section{Association between eating habits and psychological factors:}

The mean score of eating habits was compared with those who answered "yes" or "no" on psychological factors questions. No significant difference was found between those who ate because of feeling lonely (mean score $=5.91 \pm 1.99)$, and those who did not (mean score $=5.99 \pm 1.92)(p=0.580)$.

Students who answered "no" when asked if they ate until their stomach hurts had a significantly higher (mean score $=6.11 \pm 2.02)$ than those who answered "yes" (mean score $=5.77 \pm 1.85)(p=0.020)$. Students who ate because of feeling happy had healthier eating habits than those who did not, (mean score $=6.07 \pm 1.96)$ and (mean score $=5.66 \pm 1.89)$ respectively $(p=0.014)($ Table 5$)$.

\section{Factors associated with eating habits in the hierarchical multiple linear regression factors:}

Socio-demographic variables entered in the first step were age, faculty, smoking status, alcohol consumption, exercise, and accommodation. In the second step, psychological factors were entered: "eat because of feeling lonely", "feel out of control when eating", "eat so much until stomach hurts", "eat because of feeling upset or nervous", "eat because of feeling bored", and "eat because of feeling happy". In the first step non-smokers $(p<0.001)$, exercise $(p=0.002)$, and living with family $(p<0.001)$ were factors significantly associated with higher eating habits scores (Table 6). While in the second step results indicated that non-smokers $(p<0.001)$, exercise $(p=0.007)$, living with family $(p<0.001)$, and "eat because of feeling happy" ( $p=0.014)$ were associated with higher eating habits score. The total model was significant $(p<0.001)$ and accounted for $13.2 \%$ of the variance (Table 7$)$.

\section{Discussion:}

Our results revealed that only $32 \%$ of students ate regular meals daily. This is lower compared with undergraduates from China (83.6\%), Lebanon (61.4\%), Malaysia (57.6\%), and Saudi Arabia (50.5\%). The urge to change these irregular eating habits through health promotion programs is well-recommended in the literature $(19,20,25)$.

Breakfast is substantially known as the most important meal of the day (29). Skipping breakfast was found to cause obesity due to overeating in the next meal and hence raise the risk of type 2 diabetes 
mellitus (30). Additionally, daily breakfast consumption is recommended for those with a tight university schedule (31). In this study, only $32.4 \%$ ate breakfast daily. This result shares similarities with Saudi Arabia $(34.7 \%)$ and Lebanon $(31.8 \%)(19,25)$. However, our result is higher than Nigeria $(23.0 \%)$ and Jordan $(18.6 \%)(32,33)$, but much lower than Malaysia (75.6\%), Selangor $(73.6 \%)$, Brazil $(67.3 \%)$, Lebanon $(61.5 \%)(20,34-36)$.

The majority of students (69.8\%) ate meals without having snacks in between, while (53.1\%) ate snacks at least 3 times a week. This is in line with previous studies in Lebanon $(53.2 \%)$ and Syria $(53 \%)(25,26)$ but higher than studies in Saudi Arabia (26.5\%), Malaysia (42.4\%), and Nigeria (44.0\%) $(19,20,32)$. Constant snacking is a widespread habit adopted by youth $(27,37)$. Meanwhile, excessive snack eating may lead to both impairment weight loss and even weight gain (38).

Our results revealed that $64.7 \%$ of students consumed vegetables at least three times a week. This finding is higher compared with Saudi Arabian medical students, where only $20.4 \%$ ate vegetables daily, but lower than Malaysian medical students (81.8\%), who consumed more than three portions of vegetables a week $(19,20)$. The majority of respondents $(57.6 \%)$ consumed fruit at least three times a week, this finding is similar to Malaysia (48.5\%), but higher compared with undergraduates from Saudi Arabia $(11.9 \%)(19,20)$. Despite our results, a significant portion of students are not consuming enough vegetables and fruits. This may be due to the unaffordable expenses of buying such food when agriculture has been reduced significantly as a result of war (23).

Merely $31.8 \%$ of the students reported eating fast food at least three times a week. This finding is higher than a previous Syrian report where $14 \%$ of adolescents ate fast food at least four times a week (27). Fast food consumption ranged between $21.2 \%$ and $49 \%$ among undergraduates $(19,20,25,32)$. Students choose to eat fast food due to its flavor, easy access, convenience, and low price (39). making healthier meals more attainable by young people is necessary when the usual student diet is high in fat (40). Most participants (77.6\%) reported eating with their family or friends more than three times a week. The result is in line with reports from Malaysia (81.8\%), Saudi Arabia (78.3\%), and Lebanon $(76.8 \%)(19,20,25)$.

The association between eating habits score and participants socio-demographic revealed that healthier scores are high in final year undergraduates compared with first year undergraduates. This finding is in accordance with previously reported studies $(19,25)$. Students living with family reported healthy eating scores compared with students living alone or with friends. Students who practice regular exercises and have never smoked scored higher than non-athletic students and smokers or ex-smokers. Saudi Arabian medical students also showed higher eating scores in students who live with their family, play sports, and never smoked (19). These results suggest that following a healthy lifestyle elicits a healthier eating behavior.

In our study, students who reported yes because they "eat until their stomach hurts" scored lower than those who did not. The finding concurred with previous studies in Saudi Arabia and Malaysia $(19,20)$. Reports have shown that unrestrained eating habits among undergraduates indicate compulsive eating behavior (20). Furthermore, students who reported yes because they "eat when feeling happy" had higher 
eating habits scores. Other studies reported lower eating scores because of feeling lonely, upset or nervous, and bored among medical students $(19,20)$. These suggest that a healthy mental state goes hand in hand with a healthy eating lifestyle.

Although social media have become part of people's lives with a significant impact especially on younger adults, obtaining online health information has a negative effect on attitude toward eating habits (41). Data on healthy eating diets have become scarce. This study presented many factors affecting eating habits among Syrian undergraduates. These will help understand the causes of adopting unhealthy eating habits and encourage local governments to take strict actions. Measures that must be taken include creating promotional programs on healthy eating, provide an approach to encourage the consumption of healthy, safe, and affordable foods, reduce access to consumption of calorie-dense and nutrient-poor foods, and raise awareness about the importance of healthy eating habits to prevent obesity and NCD.

Like any study, there are a few limitations to be listed. The results of this study are limited to a sample of students from just one university which may not be representative of all university students in Syria. Moreover, students attending SPU are usually of high socioeconomic standards; therefore, samples from different universities may provide a more comprehensive image of university students mulling over financial status.

\section{Conclusion:}

Socio-demographic and psychological factors were significantly affected by the eating habits of the university students. Results of this study may help to create a foundation for possible interventional programs on healthy eating habits promotions across different regions. Understanding the bad eating habits may help Syrian public health authorities, university authorities, food providers, and health promotion officers plan out the required nutritional education needed by students across Syria.

\section{Abbreviations:}

NCD: Non-Communicable Disease; WHO: World Health Organization; SPU: Syrian Private University; IRB: Institutional Review Board; SPSS: Statistical Package for Social Sciences; SD: Standard Deviation.

\section{Declarations:}

\section{Ethics approval and consent to participate:}

This study was approved by the Institutional Review Board (IRB) at Syrian Private University. Written consent was obtained from all participants. Participation in the study was voluntary and participants were assured that there would be no victimization of anyone who did not want to participate or who decided to withdraw after giving consent. 


\section{Consent for publication:}

Not applicable.

\section{Availability of data and materials:}

All data related to this paper's conclusion are available and stored by the authors. All data are available from the corresponding author on reasonable request.

\section{Competing interests:}

None of the authors have any competing interests. The authors alone are responsible for the content and writing of the article. No conflict of interest is declared.

\section{Funding:}

This research received no specific grant from SPU or any other funding agency in the public, commercial or non-profit sectors.

\section{Authors' contributions:}

HA, MOA conceptualized the study, participated in the design, wrote the study protocol, and drafted the manuscript.

MM participated in the statistical analysis, FM participated in the design, did the literature search, and revision of the draft.

ZA supervised data collection and revision of the draft. All authors read and approved the final draft.

\section{Acknowledgments:}

We are thankful to the management of the Syrian Private University for the support, sponsoring, and encouragement in the field of medical training and research. We are thankful to all students who participated in this study.

\section{References}

1. Musaiger AO, Al-Hazzaa HM. Prevalence and risk factors associated with nutrition-related noncommunicable diseases in the Eastern Mediterranean region. International journal of general medicine. 2012;5:199-217. 
2. World Health Organization. Healthy diet 2020, April 29 [Available from: https://www.who.int/en/news-room/fact-sheets/detail/healthy-diet.

3. Organization WH. World report on disability 2011: World Health Organization; 2011.

4. Alwan A. Global status report on noncommunicable diseases 2010: World Health Organization; 2011.

5. Council NR, Population Co. US health in international perspective: Shorter lives, poorer health. 2013.

6. Contento IR, Koch PA, Lee H, Calabrese-Barton AJJotADA. Adolescents demonstrate improvement in obesity risk behaviors after completion of choice, control \& change, a curriculum addressing personal agency and autonomous motivation. 2010;110(12):1830-9.

7. Popkin BM, Adair LS, Ng SW. Global nutrition transition and the pandemic of obesity in developing countries. Nutrition reviews. 2012;70(1):3-21.

8. Crombie AP, Ilich JZ, Dutton GR, Panton LB, Abood DA. The freshman weight gain phenomenon revisited. Nutrition reviews. 2009;67(2):83-94.

9. Deforche B, Van Dyck D, Deliens T, De Bourdeaudhuij I. Changes in weight, physical activity, sedentary behaviour and dietary intake during the transition to higher education: a prospective study. International Journal of Behavioral Nutrition and Physical Activity. 2015;12(1):16.

10. Chin Y, Mohd NJPJoN. Eating behaviors among female adolescents in Kuantan district, Pahang, Malaysia. 2009;8(4):425-32.

11. Savige GS, Crawford D, Worsley A, Ball KJAPjocn. Food intake patterns among Australian adolescents. 2007;16(4):738-46.

12. Shi Z, Lien N, Kumar BN, Holmboe-Ottesen GJEjocn. Socio-demographic differences in food habits and preferences of school adolescents in Jiangsu Province, China. 2005;59(12):1439-48.

13. WY G, MT MN, MS Z, AS HJMJoN. Differences in eating behaviours, dietary intake and body weight status between male and female Malaysian University students. 2011;17(2).

14. Nelson MC, Story M, Larson NI, Neumark-Sztainer D, Lytle LAJO. Emerging adulthood and collegeaged youth: an overlooked age for weight-related behavior change. 2008;16(10):2205.

15. He FJ, Nowson CA, MacGregor GAJTL. Fruit and vegetable consumption and stroke: meta-analysis of cohort studies. 2006;367(9507):320-6.

16. Sogari G, Velez-Argumedo C, Gómez MI, Mora CJN. College students and eating habits: A study using an ecological model for healthy behavior. 2018;10(12):1823.

17. Tian-Ci Quek T, Tam W-S, X Tran B, Zhang M, Zhang Z, Su-Hui Ho C, et al. The global prevalence of anxiety among medical students: a meta-analysis. 2019;16(15):2735.

18. Hardcastle SJ, Thøgersen-Ntoumani C, Chatzisarantis NL. Food choice and nutrition: A social psychological perspective. Multidisciplinary Digital Publishing Institute; 2015.

19. Alzahrani SH, Saeedi AA, Baamer MK, Shalabi AF, Alzahrani AMJljogm. Eating habits among medical students at King Abdulaziz University, Jeddah, Saudi Arabia. 2020;13:77.

20. Ganasegeran K, Al-Dubai SA, Qureshi AM, Al-Abed A-AA, Rizal A, Aljunid SMJNj. Social and psychological factors affecting eating habits among university students in a Malaysian medical 
school: a cross-sectional study. 2012;11(1):1-7.

21. Sakamaki R, Toyama K, Amamoto R, Liu C-J, Shinfuku NJNj. Nutritional knowledge, food habits and health attitude of Chinese university students-a cross sectional study- . 2005;4(1):1-5.

22. Cuy Castellanos D, Holcomb JJJoAch. Food insecurity, financial priority, and nutrition literacy of university students at a mid-size private university. 2020;68(1):16-20.

23. Mohammed SA, Alkerdi A, Nagy J, Harsányi E. Syrian crisis repercussions on the agricultural sector: Case study of wheat, cotton and olives. 2020;12(3):519-37.

24. World Food Programme. WFP Syria Situation Report \#2, February 2021 2021, Mar 19 [Available from: https://reliefweb.int/report/syrian-arab-republic/wfp-syria-situation-report-2-february-2021.

25. Rizk S, Yahia N, Achkar A, Abdallah A. Eating habits and obesity among Lebanese university students. 2008.

26. Bashour HN. Survey of dietary habits of in-school adolescents in Damascus, Syrian Arab Republic. Eastern Mediterranean health journal = La revue de sante de la Mediterranee orientale = al-Majallah al-sihhiyah li-sharq al-mutawassit. 2004;10(6):853-62.

27. Musaiger AO, Kalam FJAoA, Medicine E. Dietary habits and lifestyle among adolescents in Damascus, Syria. 2014;21(2).

28. Kagan DM, Squires RLJJoCSP. Compulsive eating, dieting, stress, and hostility among college students. 1984.

29. Ahadi Z, Qorbani M, Kelishadi R, Ardalan G, Motlagh M, Asayesh H, et al. Association between breakfast intake with anthropometric measurements, blood pressure and food consumption behaviors among Iranian children and adolescents: the CASPIAN-IV study. 2015;129(6):740-7.

30. Abdull Hakim N, Muniandy N, Danish AJAJoCN. Nutritional status and eating practices among university students in selected universities in Selangor, Malaysia. 2012;4(3):77-87.

31. Tanaka M, Mizuno K, Fukuda S, Shigihara Y, Watanabe Y. Relationships between dietary habits and the prevalence of fatigue in medical students. Nutrition (Burbank, Los Angeles County, Calif). 2008;24(10):985-9.

32. Olatona FA, Onabanjo OO, Ugbaja RN, Nnoaham KE, Adelekan DA. Dietary habits and metabolic risk factors for non-communicable diseases in a university undergraduate population. Journal of Health, Population and Nutrition. 2018;37(1):21.

33. Dalky HF, Al Momani MH, Al-Drabaah TK, Jarrah SJCnr. Eating habits and associated factors among adolescent students in Jordan. 2017;26(4):538-52.

34. Isa KAM, Masuri MGJAJoF, Nutrition. The association of breakfast consumption habit, snacking behavior and body mass index among university students. 2011;1(2):55-60.

35. Perez PMP, Castro IRRd, Franco AdS, Bandoni DH, Wolkoff DBJC, coletiva s. Dietary practices of quota and non-quota students at a Brazilian public university. 2016;21:531-42.

36. El-Kassas G, Ziade FJBRI. Exploration of the dietary and lifestyle behaviors and weight status and their self-perceptions among health sciences university students in North Lebanon. 2016;2016. 
37. Amine E, Samy MJJotRSoH. Obesity among female university students in the United Arab Emirates. 1996;116(2):91-6.

38. Aparicio A, Rodríguez-Rodríguez EE, Aranceta-Bartrina J, Gil Á, González-Gross M, Serra-Majem L, et al. Differences in meal patterns and timing with regard to central obesity in the ANIBES ('Anthropometric data, macronutrients and micronutrients intake, practice of physical activity, socioeconomic data and lifestyles in Spain') Study. 2017;20(13):2364-73.

39. Rydell SA, Harnack LJ, Oakes JM, Story M, Jeffery RW, French SAJJotADA. Why eat at fast-food restaurants: reported reasons among frequent consumers. 2008;108(12):2066-70.

40. Glore SR, Walker C, Chandler AJJotACoN. Brief communication: dietary habits of first-year medical students as determined by computer software analysis of three-day food records. 1993;12(5):517-20.

41. Akram W, Kumar R, editors. A Study on Positive and Negative Effects of Social Media on Society2017.

\section{Tables}




\begin{tabular}{|c|c|}
\hline & Count (\%) \\
\hline \multicolumn{2}{|l|}{ Gender } \\
\hline Male & $330(45.3)$ \\
\hline Female & $398(54.7)$ \\
\hline \multicolumn{2}{|l|}{ BMI $\left(\mathrm{Kg} / \mathrm{m}^{2}\right)$} \\
\hline Underweight ( $\leq 18.5$ ) & $72(10.0)$ \\
\hline Normal $(18.5-24.9)$ & $443(61.7)$ \\
\hline Overweight (25.0-29.9) & $154(21.4)$ \\
\hline Obese $(\geq 30)$ & $49(6.8)$ \\
\hline \multicolumn{2}{|l|}{ Faculty } \\
\hline Medicine & $235(32.3)$ \\
\hline Dentistry & $128(17.6)$ \\
\hline Pharmacy & $187(25.7)$ \\
\hline Information technology & $66(9.1)$ \\
\hline Petroleum engineer & $55(7.6)$ \\
\hline Business administration & $57(7.8)$ \\
\hline \multicolumn{2}{|l|}{ Year of study } \\
\hline $1^{\text {st }}$ & $116(15.9)$ \\
\hline $2^{\text {nd }}$ & $183(25.1)$ \\
\hline $3^{\text {rd }}$ & $103(14.1)$ \\
\hline $4^{\text {th }}$ & $131(18.0)$ \\
\hline $5^{\text {th }}$ & $144(19.8)$ \\
\hline $6^{\text {th }}$ & $51(7.0)$ \\
\hline \multicolumn{2}{|l|}{ Place Accommodation } \\
\hline With family & $564(77.5)$ \\
\hline With friends & $61(8.4)$ \\
\hline Alone & $103(14.2)$ \\
\hline
\end{tabular}




\begin{tabular}{|ll|}
\hline Marital status & $606(83.2)$ \\
\hline In relationship & $111(15.2)$ \\
\hline Married & $11(1.5)$ \\
\hline Financial status & $4(0.5)$ \\
\hline Bad & $21(2.9)$ \\
\hline Below average & $204(28.0)$ \\
\hline Average & $413(56.7)$ \\
\hline Good & $86(11.8)$ \\
\hline Excellent & \\
\hline Smoking & $316(43.4)$ \\
\hline Smokers & $25(3.4)$ \\
\hline Previous smoker & $387(53.2)$ \\
\hline Don't smoke & \\
\hline Alcohol drinking & $135(18.5)$ \\
\hline Yes & $593(81.5)$ \\
\hline No & $534(73.3)$ \\
\hline Practicing sport (per week) & \\
\hline 3 or more times & \\
\hline Less than 3 times & \\
\hline
\end{tabular}


Table 2: Eating habits among respondents: $(n=728)$

\begin{tabular}{|c|c|c|}
\hline & & Count (\%) \\
\hline \multirow[t]{2}{*}{ Do you practice healthy eating habits? } & Yes & $259(36.0)$ \\
\hline & No & $461(64.0)$ \\
\hline \multirow[t]{2}{*}{ Do you eat regular meals? } & Yes & $233(32.0)$ \\
\hline & No & $495(68.0)$ \\
\hline \multirow[t]{2}{*}{ Frequency of having daily breakfast } & less than 3 & $306(42.0)$ \\
\hline & 3 or more & $422(57.9)$ \\
\hline \multirow[t]{2}{*}{ Frequency of having meals without snacks in between } & less than 3 & $220(30.2)$ \\
\hline & 3 or more & $508(69.8)$ \\
\hline \multirow[t]{2}{*}{ Frequency of having snacks } & less than 3 & $341(46.9)$ \\
\hline & 3 or more & $387(53.1)$ \\
\hline \multirow[t]{2}{*}{ Weekly consumption of vegetables } & less than 3 & $257(35.3)$ \\
\hline & 3 or more & $471(64.7)$ \\
\hline \multirow[t]{2}{*}{ Weekly consumption of fruits } & less than 3 & $309(42.4)$ \\
\hline & 3 or more & $419(57.6)$ \\
\hline \multirow[t]{2}{*}{ Weekly consumption of fried food } & less than 3 & $496(68.1)$ \\
\hline & 3 or more & $232(31.8)$ \\
\hline \multirow[t]{2}{*}{ Water intake (liters/day) } & 2 and more & $231(31.7)$ \\
\hline & Less than 2 & $497(68.2)$ \\
\hline \multirow[t]{2}{*}{ Meals with family and friends } & less than 3 & $163(22.4)$ \\
\hline & 3 or more & $565(77.6)$ \\
\hline \multirow[t]{4}{*}{ Food type with balanced nutrition } & Mainly meat & $18(2.5)$ \\
\hline & Mainly vegetables & $44(6.0)$ \\
\hline & Meat, vegetables, and others & $652(89.6)$ \\
\hline & others & $14(1.9)$ \\
\hline
\end{tabular}




\begin{tabular}{|c|c|c|}
\hline & & Count (\%) \\
\hline \multirow[t]{2}{*}{ Eat because of feeling lonely } & No & $419(57.6)$ \\
\hline & Yes & $309(42.1)$ \\
\hline \multirow[t]{2}{*}{ Feel completely out of control when it comes to food } & No & $414(56.9)$ \\
\hline & Yes & $314(43.1)$ \\
\hline \multirow[t]{2}{*}{ Eat so much until stomach hurts } & No & $408(56)$ \\
\hline & Yes & $320(43.6)$ \\
\hline \multirow[t]{2}{*}{ Eat because of feeling upset or nervous } & No & $493(67.7)$ \\
\hline & Yes & $235(32.3)$ \\
\hline \multirow[t]{2}{*}{ Eat because of feeling bored } & No & $252(34.6)$ \\
\hline & Yes & $476(65.4)$ \\
\hline \multirow[t]{2}{*}{ Eat because of feeling happy } & No & $193(26.5)$ \\
\hline & Yes & 535 (73.55) \\
\hline
\end{tabular}


Table 4: Association between eating habits score and socio-demographic characteristics (one way ANOVA and t-test): $(n=728)$

\section{Categorical variable}

Mean ( \pm SD) f-test/ p-value

t-test

Gender

Male

6 (1.99)

0.519

0.604

Faculty
Year of study

Female

$5.92(1.91)$

Medical

$5.98(1.96)$

0.472

0.637

Non-medical

$5.9(1.92)$

Year of study

$1 \mathrm{st}$

$6.2(19.20)$

2.377

$0.037 *$

2nd

$5.86(1.90)$

3rd

$6.16(1.76)$

4th

$5.81(1.87)$

5th

5.67 (2.08)

6th

6.55 (2.24)

Place of Accommodation

With family

6.26 (1.89)

32.173 $<0.001^{*}$

With friends

$5.16(1.73)$

Alone

4.81 (1.85)

Financial status

${ }^{1} \mathrm{Bad}$

5.16 (1.60)

2.685

0.069

${ }^{2}$ Average

Marital status

Single

5.87 (1.84)

In relationship

6.03 (2.00)

3 or more times

$5.99(1.95)$

1.017

0.309

Practicing sport

Less than 3 times

Do you smoke

Yes

$5.8(1.94)$

Do you drink alcohol

Previous smoker

Don't smoke

6.37 (1.93)

3.467

0.001 *

5.81 (1.94)

Yes

5.59 (2.02)

68.151

$<0.001$ *

No

6.08 (1.55)

6.25 (1.86)

5.87 (2.16)

0.559

0.576

5.98 (1.90) 
$\mathrm{BMI}\left(\mathrm{Kg} / \mathrm{m}^{2}\right)$
Underweight ( $\leq 18.5)$
$5.99(1.73)$
Normal $(18.5-24.9)$
$5.89(2.00)$
Overweight (25.0-29.9)
$6.23(1.77)$
Obese $(\geq 30)$
$5.73(2.13)$

1.409

0.239

${ }^{1}$ Bad: income does not provide essential needs for the family. ${ }^{2}$ Average: income provides essential needs for the family but no more. ${ }^{3}$ Good: income provides essential needs and luxury requirements.

\begin{tabular}{|c|c|c|c|}
\hline \multirow[t]{2}{*}{ Psychological factors } & \multicolumn{2}{|l|}{$\operatorname{Mean}( \pm S D)$} & \multirow[t]{2}{*}{$p$-value } \\
\hline & Yes & No & \\
\hline Eat because of feeling lonely & $5.91(1.99)$ & $5.99(1.92)$ & 0.580 \\
\hline Feel completely out of control when it comes to food & $5.84(1.84)$ & $6.05(2.03)$ & 0.150 \\
\hline Eat so much until stomach hurts & $5.77(1.85)$ & $6.11(2.02)$ & $0.020 *$ \\
\hline Eat because of feeling upset or nervous & $6.01(1.99)$ & $5.93(1.93)$ & 0.600 \\
\hline Eat because of feeling bored & $6.05(1.88)$ & $5.79(2.06)$ & 0.080 \\
\hline Eat because of feeling happy & $6.07(1.96)$ & $5.66(1.89)$ & $0.010 *$ \\
\hline
\end{tabular}

\section{Table 6: Results of the hierarchical multiple linear regression; factors associated with eating habits score- first step}

\section{Factors}

\begin{tabular}{|llll|} 
& $\boldsymbol{\beta}$ & Beta & $\boldsymbol{P}$-value \\
\hline Age (reference: $\geq 22$ years) & -0.116 & -0.029 & 0.404 \\
\hline Faculty (reference: medical faculties) & 0.058 & 0.013 & 0.720 \\
\hline Smoking (reference: non-smoker) & 0.625 & 0.160 & $0.000^{\star}$ \\
\hline Alcohol (reference: no) & -0.269 & -0.054 & 0.151 \\
\hline Sport exercise (reference: yes) & 0.488 & 0.111 & $0.002^{\star}$ \\
\hline Accommodation (reference: live with family) & 1.281 & 0.275 & $0.000^{\star}$ \\
\hline
\end{tabular}


Table 7: Results of the hierarchical multiple linear regression; factors associated with eating habits score- second step

\begin{tabular}{llll} 
Factors & \multicolumn{3}{c}{ Second step } \\
\cline { 2 - 4 } & $\boldsymbol{B}$ & Beta & $\boldsymbol{P}$-value \\
\hline Age (reference: $\geq$ 22 years) & -0.089 & -0.023 & 0.521 \\
\hline Faculty (reference: medical faculties) & 0.056 & 0.012 & 0.729 \\
\hline Smoking (reference: non-smoker) & 0.593 & 0.152 & $p<0.001^{*}$ \\
\hline Alcohol (reference: no) & -0.287 & -0.057 & 0.124 \\
\hline Sport exercise (reference: yes) & 0.426 & 0.097 & $0.007^{*}$ \\
\hline Accommodation (reference: live with family) & 1.280 & 0.275 & $p<0.001^{*}$ \\
\hline Eat because of feeling lonely (reference: no) & 0.174 & 0.044 & 0.275 \\
\hline Feel completely out of control when it comes to food (reference: no) & 0.218 & 0.055 & 0.142 \\
\hline Eat so much until stomach hurts (reference: no) & 0.178 & 0.045 & 0.219 \\
\hline Eat because of feeling upset or nervous (reference: no) & -0.059 & -0.014 & 0.722 \\
\hline Eat because of feeling bored (reference: no) & -0.071 & -0.017 & 0.675 \\
\hline Eat because of feeling happy (reference: no) & -0.412 & -0.093 & $0.014^{\star}$ \\
\hline
\end{tabular}

